\title{
EDITORIAL
}

\section{A new look at bronchopulmonary dysplasia classification}

\section{Journal of Perinatology (2006) 26, 207-209. doi:10.1038/sj.jp.7211449}

In reading the literature over many years regarding bronchopulmonary dysplasia (BPD), there has been an evolution of and some difficulties in the terminology of this important disease. The original definition ${ }^{1}$ of a supplemental oxygen requirement and radiographic changes at 28 days became problematic as the care and survival of less mature infants became the norm. The term 'chronic lung disease (CLD)' came along when very immature infants who clearly were developing BPD but were not yet 28 days needed to have a diagnosis. In addition, we then began to define BPD as supplemental oxygen at 36 weeks postmenstrual age'. ${ }^{2}$ This is a much better definition but not truly a 'term,' and, then, many neonatologists were reluctant to 'diagnose' BPD until 36 weeks postmenstrual age (PMA), encouraging the use of the less-specific term CLD prior to that age.

The NIH workshop on BPD members proposed a new definition ${ }^{3}$ including specific criteria for 'mild,' 'moderate' and 'severe' BPD. I believe these are useful. A large study by Ehrenkranz et $a l^{4}{ }^{4}$ suggests that this definition is useful in predicting longer-term pulmonary and neurodevelopmental outcomes. However, the terminology of 'mild, moderate and severe' are, in my opinion, too generic, used commonly already in a haphazard manner, and thus not specific. Also, we have been asked by the workshop members to use the term 'bronchopulmonary dysplasia' rather than the more generic 'chronic lung disease' and we should. The latter term is nonspecific and also used by physicians caring for adult patients with chronic lung disease; 'BPD' lets everyone know that we are referring to a neonatal pediatric lung problem.

I offer the following solution:

The term 'BPD' can be used clinically as the attending neonatologist sees fit. However, if and when the criteria for meeting the specific Jobe-Bancalari NIH consensus definitions are evaluated, the words 'Grade X' will be applied as follows for those infants meeting the NIH definition:

'Grade 1 BPD' this is the same as 'mild' BPD as defined by the NIH workshop, that is, supplemental oxygen for $\geqslant 28$ days and on room air at 36 weeks PMA or at discharge (for infants $<32$ weeks at birth) or at 56 days or at discharge (for infants $\geqslant 32$ weeks at birth).

'Grade 2 BPD' this is the same as 'moderate' BPD, that is, supplemental oxygen for $\geqslant 28$ days and a need for supplemental oxygen $<30 \%$ at 36 weeks PMA/discharge (for $<32$ weeks) or at 56 days/discharge (for infants $\geqslant 32$ weeks).

'Grade 3 BPD' this is the same as 'severe' BPD, that is, supplemental oxygen for $\geqslant 28$ days and a need for $\geqslant 30 \%$ oxygen or on nasal CPAP or mechanical ventilation at 36 weeks PMA discharge ( $<32$ weeks) or at 56 days/discharge $(\geqslant 32$ weeks).

All references to oxygen refer to effective oxygen concentration. (The NIH workshop definition was not as specific but this was implied.) User-friendly tables for nasal cannula effective oxygen concentration are available from Madan et al..$^{5}$ based on earlier work by Benaron and Benitz. ${ }^{6}$

Then, when the specific term 'Grade X BPD' is used for clinical purposes, for example at discharge, including for 'in-house' quality assurance data, or in clinical research studies as an important outcome, all will know that this refers specifically to the Jobe-Bancalari NIH consensus definition. This now would not preclude an attending neonatologist from making a clinical diagnosis of BPD (without the 'Grade') before 36 weeks PMA. Also, the less-preferred term CLD would be unnecessary (and perhaps editors could request authors to consider using BPD instead).

A long-standing concern in identifying neonates with BPD is that the disease has been essentially defined by its treatment, that is, receiving supplemental oxygen, rather than a physiologic need for oxygen. However, there is little agreement on the definition of hypoxia requiring treatment and there is variability as to which infants receive supplemental oxygen, based on the practice of individual neonatologists or the standard practice in a given NICU. Obviously, the target saturation range itself will impact on the prevalence of BPD. To tackle this, the NIH workshop members began to work on a physiologic definition of BPD, but it was not available at the time of the Jobe-Bancalari criteria publication. Since that time, Walsh et al. ${ }^{7}$ have utilized the neonates at centers in the NIH Neonatal Research Network in developing a physiologic definition. At the current time, this is not in common practice. However, as the use of the physiologic definition becomes more prevalent, alternate BPD Grades modified to have a 'P' added could be used, denoting a formal assessment for the need for supplemental oxygen at 36 weeks PMA/discharge or at 56 days/discharge (see Table 1). 
Table 1 Bronchopulmonary dysplasia classification

\begin{tabular}{|c|c|}
\hline Grade 1 BPD & $\begin{array}{l}\text { Supplemental oxygen for } \geqslant 28 \text { days and on room air at } 36 \text { weeks PMA or at discharge (for infants }<32 \text { weeks at birth) or at } 56 \text { days or at discharge } \\
\text { (for infants } \geqslant 32 \text { weeks at birth), whichever comes first }\end{array}$ \\
\hline Grade 2 BPD & $\begin{array}{l}\text { Supplemental oxygen for } \geqslant 28 \text { days and receiving supplemental effective oxygen }<30 \% \text { at } 36 \text { weeks PMA/discharge ( }<32 \text { weeks) or at } 56 \text { days/ } \\
\text { discharge }(\geqslant 32 \text { weeks) }\end{array}$ \\
\hline Grade 3 BPD & $\begin{array}{l}\text { Supplemental oxygen for } \geqslant 28 \text { days and receiving supplemental effective oxygen } \geqslant 30 \% \text { oxygen or on nasal CPAP or mechanical ventilation at } 36 \\
\text { weeks PMA/discharge ( }<32 \text { weeks) or at } 56 \text { days/discharge ( } \geqslant 32 \text { weeks) }\end{array}$ \\
\hline Grade 1P BPD & $\begin{array}{l}\text { Supplemental oxygen for } \geqslant 28 \text { days with documentation that saturations are } \geqslant 90 \% \text { in room air at } 36 \text { weeks PMA/discharge }(<32 \text { weeks }) \text { or at } 56 \\
\text { days/discharge }(\geqslant 32 \text { weeks) }\end{array}$ \\
\hline Grade 2P BPD & $\begin{array}{l}\text { Supplemental oxygen for } \geqslant 28 \text { days with a documented need for supplemental effective oxygen }<30 \% \text { based on failure to maintain oxygen } \\
\text { saturation } \geqslant 90 \% \text { in a formal timed weaning trial at } 36 \text { weeks PMA/discharge ( }<32 \text { weeks) or at } 56 \text { days/discharge ( } \geqslant 32 \text { weeks) }\end{array}$ \\
\hline Grade & $\begin{array}{l}\text { Supplemental oxygen for } \geqslant 28 \text { days and on CPAP or mechanical ventilation or supplemental effective oxygen } \geqslant 30 \% \text { based on failure to maintain } \\
\text { oxygen saturation } \geqslant 90 \% \text { in a formal timed weaning trial at } 36 \text { weeks PMA/discharge ( }<32 \text { weeks) or at } 56 \text { days/discharge ( } \geqslant 32 \text { weeks) }\end{array}$ \\
\hline
\end{tabular}

Modified from Jobe and Bancalari, Am J Respir Crit Care Med 2001; 163: 1723-1729.

'P' refers to use of the physiologic definition of BPD based on Walsh et al., Pediatrics 2004; 114: 1305-1311.

All references to oxygen refer to effective oxygen concentration delivered by hood or cannula (user-friendly tables available in Madan et al., Pediatrics 2005 ; 115 : e450-e457 based on Benaron and Benitz, Arch Pediatr Adolesc Med 1994; 148(3): 294-300).

The physiologic definition of BPD has focused on the overutilization of supplemental oxygen, by requiring a formal weaning trial if oxygen saturations are 'too high.' This protects against babies receiving oxygen who 'may not need it,' and a false inflation of the prevalence of BPD in a given NICU. However, somewhat less attention has been devoted to the opposite issue, that is, that there may be babies in some units who are not receiving oxygen who 'should be' and therefore a false 'under-diagnosing' of BPD. This is not addressed directly by the NIH definition but is addressed by Walsh et al. ${ }^{7}$ in that to have a diagnosis of 'no BPD' saturation must be $\geqslant 90 \%$ in room air. Also, the lower cutoff for 'failing' the trial of weaning was $90 \%$; we infer then that these NICUs did not routinely have infants at 36 weeks PMA with saturations $<90 \%$. The cutoff of $90 \%$ was based on a survey of the NICHD Neonatal Research Network members as there is little rigorous data to determine the 'best' lower saturation target at this age. The requirement of a saturation of $\geqslant 90 \%$ for room air patients provides greater uniformity in categorizing babies not receiving supplemental oxygen, rather than being based solely on clinical discretion.

There is one remaining and unstudied issue in combining the physiologic definition with the original NIH consensus definition. In the studies by Walsh et $a l^{7}$, the infants who were receiving cannula/hood effective oxygen of $\geqslant 30 \%$ with saturation $90-96 \%$ were not subjected to a timed weaning trial because it was felt (logically) they would be unlikely to wean all the way to room air. However, the goal of this work was to create a physiologic definition of BPD based on a need for supplemental oxygen at 36 weeks PMA as a 'yes/no' categorization. For severity categorization, the infant in $\geqslant 30 \%$ with saturations $90-96 \%$ may, in fact, be weanable to $<30 \%$, which would alter the grade assigned. This will need to be studied in the future but for the current classification proposed, the requirement for a timed weaning trial will be for all infants on cannula or hood oxygen. Ultimately, the timed weaning trial may be obviated if consensus target saturations become well-established and used widely.

Table 1 summarizes the classification system. Grades 1, 2 and 3 are based on oxygen treatment and the original NIH workshop definition; Grades 1P, 2P and 3P are based on combining the NIH consensus framework with the physiologic definition using oxygen saturation requirements.

I am sure that many of the NIH workshop members worked very hard examining and discussing data to develop these definitions and it is important that they be used widely and consistently. A more precise definition of BPD and its severity will be helpful in the many necessary future clinical research studies.

\section{Acknowledgments}

I thank my colleagues Satyan Lakshminrusimha and Vasanth Kumar for their valuable discussions regarding this editorial.

Rita M Ryan

Division of Neonatology, Department of Pediatrics, State University of New York at Buffalo, Women \& Children's Hospital of Buffalo, Buffalo, NY, USA E-mail: rryan@upa.chob.edu

\section{References}

1 Northway Jr WH, Rosan RC, Porter DY. Pulmonary disease following respirator therapy of hyaline-membrane disease. Bronchopulmonary dysplasia. N Engl J Med 1967; 276: 357-368. 
2 Shennan AT, Dunn MS, Ohlsson A, Lennox K, Hoskins EM. Abnormal pulmonary outcomes in premature infants: prediction from oxygen requirement in the neonatal period. Pediatrics 1988; 82(4): 527-532.

3 Jobe AH, Bancalari E. Bronchopulmonary dysplasia. Am J Respir Crit Care Med 2001; 163(7): 1723-1729.

4 Ehrenkranz RA, Walsh MC, Vohr BR, Jobe AH, Wright LL, Fanaroff AA et al. Validation of the National Institutes of Health Consensus definition of Bronchopulmonary Dysplasia. Pediatrics 2005; 116(6): 1353-1360.
5 Madan A, Brozanski BS, Cole CH, Oden NL, Cohen G, Phelps DL et al. A pulmonary score for assessing the severity of neonatal chronic lung disease. Pediatrics 2005; 115(4): e450-e457.

6 Benaron DA, Benitz WE. Maximizing the stability of oxygen delivered via nasal cannula. Arch Pediatr Adolesc Med 1994; 148(3): 294-300.

7 Walsh MC, Yao Q, Gettner P, Hale E, Collins M, Hensman A et al. Impact of a physiologic definition on bronchopulmonary dysplasia rates. Pediatrics 2004; 114(5): 1305-1311. 